\title{
ZONA DO EURO: ESTRUTURA PRODUTIVA E EMISSÕES DE GASES DO EFEITO ESTUFA
}

\author{
Clévia Israel Faria França ${ }^{1}$ \\ Irene Domenes Zapparoli ${ }^{2}$ \\ Umberto Antônio Sesso Filho ${ }^{3}$
}

\begin{abstract}
Resumo: O objetivo é correlacionar a estrutura produtiva da Zona do Euro e seus impactos no uso da energia. Na metodologia foram calculados os multiplicadores e geradores de energia renovável e não renovável e o efeito transbordamento, utilizando a matriz insumo-produto e a base de dados do World Input-Output Database. Nos resultados os multiplicadores de produção na relação uso de energia e poluição atmosférica, foi equipamentos de transporte. Nos geradores tem-se Refino de Petróleo e Combustível Nuclear e Eletricidade, Gás e Água. A utilização de energia proveniente do aumento da produção é transbordada para fora do bloco, o que indica insuficiente infraestrutura interna. Devido a um trade-off entre o aumento da produção e a utilização de energia, seria importante descobrir as vantagens e desvantagens de cada país quanto a tais escolhas, sendo esta, uma sugestão para trabalhos futuros.
\end{abstract}

Palavras-chave: Zona do Euro; Energias; Matriz Insumo-produto

\section{EURO ZONE: PRODUCTION STRUCTURE AND GREENHOUSE GAS EMISSIONS}

Abstract: The aim is to correlate the productive structure of the Eurozone and its impacts on the use of energy. In the methodology, multipliers and generators of renewable and nonrenewable energy and the overflowing effect were calculated using the inputs-product matrix and the World Input-Output Database. In the results the production multipliers in relation to energy use and atmospheric pollution, was transportation equipment. The generators have Refining Oil and Nuclear Fuel and Electricity, Gas and Water. The use of energy from the increase in production is overflowed out of the block, which indicates insufficient internal infrastructure. Due to a trade-off between the increase in production and the use of energy, it would be important to discover the advantages and disadvantages of each country for such choices, this being a suggestion for future work.

Keywords: Eurozone; Energies; Input-Output Matrix

\section{ZONA EURO: ESTRUCTURA DE PRODUCCIÓN Y EMISIONES DE GASES DE EFECTO INVERNADERO}

Resumen: El objetivo es correlacionar la estructura productiva de la Eurozona y sus impactos en el uso de la energía. En la metodología, los multiplicadores y generadores de energía renovable y no renovable y el efecto rebosante se calcularon utilizando la matriz de insumosproductos y la base de datos de la World Input-Output Database. En los resultados los multiplicadores de la producción en lo referente al uso de energía y a la contaminación atmosférica, eran equipo del transporte. Los generadores tienen aceite de refinación y

\footnotetext{
${ }^{1}$ Mestre em Economia pela Universidade Estadual de Londrina - UEL, Londrina, Paraná, Brasil. E-mail: profclevia@hotmail.com

${ }^{2}$ Professora Dra. do Programa de Pós-Graduação em Economia Regional, Universidade Estadual de Londrina. Paraná, Brasil. E-mail: zapparoli@uel.br

${ }^{3}$ Professor Dr. coordenador do Programa de Pós-Graduação em Economia Regional, Universidade Estadual de Londrina. Paraná, Brasil. E-mail: uma-sesso@uel.br
} 
combustible nuclear y electricidad, gas y agua. El uso de la energía del aumento de la producción se desborda del bloque, lo que indica una infraestructura interna insuficiente. Debido a un intercambio entre el aumento de la producción y el uso de la energía, sería importante descubrir las ventajas y desventajas de cada país en cuanto a estas opciones, siendo esta una sugerencia para el trabajo futuro.

Palabras clave: Zona del euro; Energías; Matriz de entrada-producto

\section{INTRODUÇÃO}

$\mathrm{Na}$ sociedade moderna a energia é essencial para gerar bens com sustentação em recursos naturais. No entanto, o desenvolvimento e o crescimento econômico compartilham o conhecimento da necessidade de um abastecimento adequado e seguro de energia. Uma vez que o mundo se tornou interdependente em termos de processos produtivos, as utilizações dos recursos energéticos impactam o ambiente.

Dentre as principais discussões a respeito de energia dar-se-á especial atenção ao uso de fontes renováveis de energia como água, o vento, o sol e a biomassa e o uso de recursos não renováveis como carvão mineral, petróleo, gás natural e o urânio

Em um contexto de globalização econômica e franco crescimento do consumo em escalas nunca antes observadas, destaca-se a chamada Zona do Euro, que se refere a uma união monetária dentro da União Europeia. Constituída pelos países Alemanha, Áustria, Bélgica, Chipre, Eslováquia, Eslovênia, Estônia, Finlândia, França, Irlanda, Itália, Letônia, Lituânia, Luxemburgo, Malta, Holanda, Portugal, Grécia e Espanha, os quais adotaram o euro como única moeda.

Nesta conjuntura os países da Zona do Euro, por demonstrarem algumas singularidades, seja pelo tamanho ou dinamismo, têm se tornado alvo de crescente interesse no cenário internacional. No entanto, junto com o crescente poder econômico, cresce o impacto desses países sobre o meio ambiente. Nesse sentido, o objetivo geral consiste em correlacionar os impactos ambientais proveniente do uso de energia renovável e não renovável na estrutura produtiva da Zona do Euro nos anos de 1995 e 2009.

Na metodologia utiliza-se como ferramenta a matriz insumo-produto, sendo que a base de dados foi extraída do World Input-Output Database (WIOD), a qual contempla 35 setores produtivos na economia de 40 países, mais o restante do mundo. Porém, cabe salientar que neste estudo foram analisados exclusivamente os países membros da Zona do Euro.

Esta pesquisa está organizada da seguinte maneira: além da introdução, apresenta a fundamentação teórica, a metodologia de pesquisa, apresentação e análise dos resultados 
quanto ao cálculo dos multiplicadores, identificação dos geradores e estimação do transbordamento e, por fim, as considerações finais.

\section{Aquecimento global e poluição térmica a partir do uso de energias}

Na sociedade moderna, a energia é utilizada para a constituição de bens, com base em recursos naturais, pois fornece serviços que beneficiam a coletividade, sendo que, em 2017, menos de $1 \%$ do trabalho efetuado nos produtos industrializados dependem da força muscular como fonte de energia. Hinrichs, Kleinbach e Reis (2014; DALY, 1969) apontam que a energia é mais bem descrita pelo que ela pode fazer. Não é possível "ver" a energia, apenas seus efeitos; não é possível fazê-la, apenas usá-la; e não é possível destruí-la, apenas desperdiçá-la.

Em todo o mundo os governos têm em suas políticas energéticas o uso de combustíveis fósseis, carvão, petróleo, gás natural e urânio, sendo que, tais bases representam altos custos de impactos socioambientais que sustentaram o crescimento e o desenvolvimento econômico das últimas décadas (MENTONE, 2015; CASLER, 1997).

Goldemberg e Lucon (2008) indicam que a produção de energia no século 1920 foi dominada por combustíveis fósseis o que representavam, ainda no início do século 21 , cerca de $80 \%$ de toda a energia produzida no mundo. Hinrichs, Kleinbach e Reis (2014) constataram que algumas mudanças foram afetadas pela crise global, mas a tendência ainda está correta. Em comparação, os países em desenvolvimento estão experimentando um rápido aumento no consumo de energia per capita. Ao mesmo tempo que representam $80 \%$ da população mundial, eles consomem apenas um terço da energia global. Todavia espera-se que essa participação aumente em torno de $40 \%$ na próxima década, em razão da rápida expansão industrial, do grande crescimento populacional, da urbanização e do aumento dos salários, permitindo que as famílias adquiram aparelhos eletrônicos e automóveis.

Vich e Mansor (2009) asseguram que o panorama mundial está rapidamente se alterando devido a três grandes preocupações da humanidade: meio ambiente, energia e economia global, sendo que, estas áreas estão completamente interligadas. Para Santin e Alvim (2008) o efeito estufa é um fenômeno natural por meio do qual é constante a temperatura da atmosfera o que possibilita a existência de vida no planeta, na tabela 1 tem-se a composição dos GEEs na atmosfera. 
Tabela 1 - Participação dos gases de efeito estufa nas emissões mundiais, em 2009

\begin{tabular}{lrc}
\hline \multicolumn{1}{c}{ Gases de Efeito Estufa } & Emissões $(\mathbf{G g})$ & \multicolumn{1}{c}{$\%$} \\
\hline Dióxido de carbono $-\mathrm{CO}_{2}$ & $24.870 .226,63$ & 95,94 \\
Metano $-\mathrm{CH}_{4}$ & $286.154,83$ & 1,10 \\
Óxido nitroso - $\mathrm{N}_{2} \mathrm{O}$ & $11.098,89$ & 0,04 \\
Óxidos de nitrogênio - $\mathrm{NO}_{\mathrm{X}}$ & $100.675,22$ & 0,39 \\
Óxidos de enxofre - $\mathrm{SO}_{\mathrm{X}}$ & $111.741,68$ & 0,43 \\
Monóxido de carbono - CO & $398.584,53$ & 1,54 \\
Amônia - $\mathrm{NH}_{3}$ & $31.026,39$ & 0,44 \\
Compostos orgânicos voláteis não metânicos - NMVOC & $113.580,90$ & 0,12 \\
\hline TOTAL & $\mathbf{2 5 . 9 2 3 . 0 8 9 , 0 7}$ & $\mathbf{1 0 0 , 0 0}$ \\
\hline
\end{tabular}

Fonte: World Input-Output Database (WIOD, 2017).

A União Europeia, bem como os países que compõem a Zona do Euro, enfrentam procura crescente de energia, preços voláteis e perturbações do abastecimento. Por outro lado, buscam reduzir o impacto ambiental do setor da energia. Não obstante, a Agência Europeia do Ambiente (2017) assinala que, em 2010, a energia solar fotovoltaica foi a principal responsável pelas novas capacidades instaladas, seguida do gás e da energia eólica.

De acordo com o Parlamento Europeu (2017), foram definidas as seguintes metas: geração de $12 \%$ do consumo de energia e de $22,1 \%$ do consumo de eletricidade a partir de fontes renováveis até 2010, além de propor uma meta obrigatória de $20 \%$ para a geração de energia de consumo a partir de fontes de energia renováveis até 2020, uma meta obrigatória de $10 \%$ para a utilização de biocombustíveis no consumo de combustíveis para transportes até 2020.

Souza, Zapparoli, Sesso Filho et al. (2015) identificam que dentre as possíveis causas que fazem os países membros do BRIC ocuparem as primeiras posições no ranking dos países mais poluentes, encontram-se as suas fontes energéticas.

Os impactos do uso da energia renovável e não renovável são tratados na literatura por meio de muitas metodologias. Portanto, é crescente a utilização de modelos de insumo-produto, em questões ambientais cuja abordagem advém de questões econômicas.

Existem estudos importantes a respeito da aplicação de Modelos de Insumo-Produto no uso de energia, como os trabalhos nacionais de Mattos et al. (2008), Simas (2012), Firme e Perobelli (2012), Souza, Zapparoli, Sesso Filho et al. (2015), Ferreira Neto et al. (2012), Montoya e Pasqual (2015), Duarte (2008) e Esteves (2017) e os trabalhos internacionais de Machado, Schaeffer, e Worrell (2001), Liu et al. (2010) e Tang, Snowden e Höök (2013) os quais fizeram uso do método para análise da utilização da energia renovável e não renovável na estrutura produtiva.

Portanto, para avançar na discussão apresentada, essa pesquisa tem por objetivo investigar os impactos no uso da energia renovável e não renovável na estrutura produtiva da Zona do Euro.

\section{MATERIAIS E MÉTODOS}


Os países da Zona do Euro estão estre os líderes mundiais no uso de energias renováveis, tanto no sentido de desenvolvimento de métodos quanto de utilização. Além de receber incentivos e financiamentos por parte do governo.

De acordo com o Eco desenvolvimento de energia (2010), as fontes renováveis de energia responderam por 19,9\% do consumo total de energia na Zona do Euro bem como na União Europeia em 2009, e correspondem a $62 \%$ da nova capacidade de geração de eletricidade instalada no mesmo período. Em relação ao consumo de energia hidrelétrica respondeu pela maior parcela entre as fontes renováveis com $(11,6 \%)$, seguida pela energia eólica $(4,2 \%)$, biomassa $(3,5 \%)$ e solar $(0,4 \%)$. Sobre a nova capacidade de geração instalada a energia eólica ficou em primeiro $(37,1 \%)$. Sendo que, em relação as fontes não renováveis o destaque foi para o gás (24\%).

A fim de avaliar a associação relacionada à trajetória da estrutura produtiva e da demanda, a pesquisa emprega a metodologia de decomposição estrutural via matriz insumo-produto mundial, nos anos de 1995 e 2009 com o objetivo de correlacionar a estrutura produtiva da Zona do Euro e seus impactos no uso da energia.

\section{Fontes e Base de Dados}

É utilizada a base de dados que pertence ao World Input-Output Database - WIOD (Banco de Dados Mundial de Insumo-Produto). Portanto, foram empregados dados divulgados na página eletrônica WIOD, usados nas tabelas de insumo-produto da Zona do Euro, nos anos de 1995 e 2009.

A finalidade do desenvolvimento dessa fonte de dados é explorar as consequências da globalização sobre os componentes e agregados econômicos em diversos países (TIMMER, 2012). Portanto, apesar de existirem 35 setores produtivos, como consta no quadro 1, o setor de Residências Particulares com Empregados (35) não contém dados disponíveis para grande maioria dos países. Sendo assim, optou-se por analisar apenas 34 setores neste estudo.

Quadro 1 - Setores produtivos da economia para a matriz insumo-produto - WIOD

\section{Setores Produtivos da Economia}

\begin{tabular}{llll}
\hline 1 & Agropecuária & 19 Venda e manutenção de veículos automotores \\
2 & Extrativismo mineral & 20 Atacado \\
3 & Alimentos, bebidas e fumo & 21 Varejo \\
4 & Têxteis & 22 Hotéis e restaurantes \\
5 & Vestuário & 23 Transporte terrestre \\
6 & Madeira e produtos da madeira & 24 Transporte aquático \\
7 & Papel, celulose e gráfica & 25 Transporte aéreo \\
8 & Refino de petróleo e combustível nuclear & 26 Outras atividades de suporte ao Transporte \\
9 & Indústria química & 27 Comunicações \\
10 & Borracha e plástico & 28 Intermediação financeira \\
11 & Outros minerais não metálicos & 29 Aluguéis \\
12 & Metalurgia & 30 Serviços prestados às empresas \\
13 & Máquinas e equipamentos & 31 Administração pública
\end{tabular}


14 Eletrônicos e equipamentos ópticos

15 Equipamentos de transporte

16 Manufatura e reciclagem

17 Eletricidade, gás e água

18 Construção
32 Educação

33 Saúde

34 Outros serviços

35 Residências particulares com empregados

Fonte: Adaptado de World Input-Output Database (WIOD, 2017).

É abordado a estrutura produtiva mundial e seus impactos no uso da energia renovável e não renovável, considerando a dependência direcionada a insumos e mercados. Portanto, no que se refere aos resultados e discussões, esta pesquisa se concentra na estrutura produtiva da Zona do Euro.

Matriz de Insumo-Produto

Leontief (1988) afirma que a forma mais simples de descrever a matriz insumoproduto nacional, é afirmar que é demonstrado os fluxos de bens e serviços entre os diversos setores da economia de um país ${ }^{4}$, em relação a determinado período e em termos monetários. Portanto, a matriz indica todas as inter-relações de compra e venda de uma determinada economia. É importante destacar que, de forma específica, o método de insumo produto é uma adaptação da teoria neoclássica de equilíbrio geral para o estudo empírico da interdependência quantitativa entre as atividades econômicas inter-relacionadas (LEONTIEF, 1988, p. 73).

Chiang e Wainwright (2006), apresentam a versão estática, em que esta pautado este trabalho, portanto o modelo de Leontief apresenta a questão relacionada a que nível de produto cada uma das $n$ indústrias de uma economia deve produzir, de modo que seja exatamente suficiente para satisfazer a demanda total por aquele produto.

\begin{tabular}{|c|c|c|c|c|c|}
\hline \multirow[b]{2}{*}{$\begin{array}{l}\text { Origem da } \\
\text { Produção (Venda) }\end{array}$} & \multicolumn{3}{|c|}{$\begin{array}{l}\text { Demandas Intermediárias } \\
\text { (ou Intersetoriais) }\end{array}$} & \multirow{2}{*}{$\begin{array}{c}\text { Demanda Final } \\
(\mathrm{C}+\mathrm{I}+\mathrm{G}+ \\
\mathrm{X})\end{array}$} & \multirow{2}{*}{$\begin{array}{l}\text { Valor } \\
\text { Bruto de } \\
\text { Produçãa } \\
\quad \text { o }\end{array}$} \\
\hline & $\begin{array}{l}\text { Agricultura } \\
\text { (Setor 1) }\end{array}$ & $\begin{array}{l}\text { Indústria } \\
\text { (Setor 2) }\end{array}$ & $\begin{array}{l}\text { Serviços } \\
\text { (Setor 3) }\end{array}$ & & \\
\hline \multirow{3}{*}{$\begin{array}{l}\text { Agricultura (Setor 1) } \\
\text { Indústria (Setor 2) } \\
\text { Serviços (Setor 3) }\end{array}$} & $\mathrm{Z}_{11}$ & $\mathrm{Z}_{12}$ & $\mathrm{Z}_{13}$ & $\mathrm{y}_{1}$ & $\mathrm{x}_{1}$ \\
\hline & $\mathrm{Z}_{21}$ & $\mathrm{z}_{22}$ & $\mathrm{z}_{23}$ & $\mathrm{y}_{2}$ & $\mathrm{X}_{2}$ \\
\hline & $\mathrm{z}_{31}$ & $\mathrm{z}_{32}$ & $\mathrm{Z}_{33}$ & $\mathrm{y}_{3}$ & $\mathrm{X}_{3}$ \\
\hline Importações (M) & $\mathrm{m}_{1}$ & $\mathrm{~m}_{2}$ & $\mathrm{~m}_{3}$ & & \\
\hline Imposto Indireto Líquido (IIL) & $\mathrm{iil}_{1}$ & $\mathrm{iil}_{2}$ & $\mathrm{iil}_{3}$ & & \\
\hline $\begin{array}{l}\text { Valor Adicionado } \\
\text { (salários+juros+alugueis+lucros) }\end{array}$ & $\mathrm{va}_{1}$ & $\mathrm{va}_{2}$ & $\mathrm{va}_{3}$ & & \\
\hline Valor Bruto de Produção & $\mathrm{x}_{1}$ & $\mathrm{x}_{2}$ & $\mathrm{x}_{3}$ & & \\
\hline
\end{tabular}

\footnotetext{
4 “O método foi originalmente desenvolvido para analisar e avaliar as relações entre os diversos setores produtivos e de consumo de uma economia nacional, mas vem sendo aplicado ao estudo de sistemas econômicos menores, como uma área metropolitana, ou até mesmo ao estudo de uma grande empresa individual integrada, também vem sendo aplicado à análise das relações econômicas internacionais"
} 
FRANÇA, C.I.F.; ZAPPAROLI, I.D.; SESSO FILHO, U.A.

\begin{tabular}{|l|c|c|c|}
\hline GEE/Gases de Efeito Estufa & gee $_{1}$ & $\mathrm{gee}_{2}$ & $\mathrm{gee}_{3}$ \\
\hline Energia Renovável & $\mathrm{er}_{1}$ & $\mathrm{er}_{2}$ & $\mathrm{er}_{3}$ \\
\hline Energia Não Renovável & $\mathrm{enr}_{1}$ & $\mathrm{enr}_{2}$ & $\mathrm{enr}_{3}$ \\
\hline
\end{tabular}

Quadro 2 - Relações de Insumo-Produto em um sistema nacional (economia com três setores)

Fonte: Adaptado de Lopes e Vasconcellos (2008, p. 54).

A relação $\mathrm{X}=(\mathrm{I}-\mathrm{A})^{-1 *} \mathrm{Y}$ resume a capacidade explicativa da análise de insumo-produto no tocante ao comportamento das economias nacionais. Contudo, verifica-se como um impacto na demanda final (Y) afeta o valor da produção (X) e este, por sua vez, afeta outras varáveis como emprego, salário, importação, impostos e etc., assim, é possível observar a importância deste método para os países. É importante ressaltar a análise inter-regional de insumo-produto, conforme Quadro 2.

Os fluxos intersetoriais são determinados por fatores tecnológicos e econômicos em uma economia, segundo Leontief (1951 apud GUILHOTO, 2001), pode ser também representado matricialmente da seguinte forma:

$$
\mathrm{x}=\mathrm{Ax}+\mathrm{y}
$$

Em que:

$\mathbf{x}=$ vetor $(n \times 1)$ com o valor bruto da produção;

$\boldsymbol{y}=$ vetor $(n \times 1)$ com a demanda final setorial e;

$\mathbf{A}=$ matriz $(n \times n)$ com os coeficientes técnicos de produção, na qual o elemento $a_{i \bar{i}}$ representa a participação do produto do setor $i$ sobre a produção do setor $j$.

Tomando as relações de compra e venda de insumo entre os setores presentes na economia constrói-se a matriz de consumo intermediário, por meio da qual se obtém a matriz $\mathbf{A}$. Sendo $\mathbf{Z}$ a matriz de consumo intermediário, o elemento $z_{i j}$ sinaliza o valor demandado pelo setor $j$ do setor $i$. Desse modo, fazendo $z_{i j} / x_{i j}$ obtém-se o elemento $a_{i j}$ da matriz $\mathbf{A}$.

Isolando $\mathbf{x}$ obtém-se:

$$
\begin{gathered}
\mathbf{x}=\mathbf{B y} \\
\mathbf{B}=(\mathbf{I}-\mathbf{A})^{-\mathbf{1}}
\end{gathered}
$$

A matriz B recebe o nome de inversa de Leontief. De acordo com Guilhoto 2001, a partir do modelo básico, é possível trabalhos que abordem as extensões como endogeneização do consumo das famílias para estudos relacionados à distribuição de renda e análises estruturais e de impacto.

Geradores

Miller e Blair (2009) identificam que por meio dos coeficientes diretos e da matriz de Leontief pode-se estimar para cada setor da economia, o quanto é gerado direta e indiretamente, no que diz 
respeito ao emprego, importações, impostos, salários, valor adicionado e demais variáveis para cada unidade monetária produzida para a demanda final, ou seja:

$$
G V_{j}=\sum_{i=1}^{n} b_{i j} v_{i}
$$

em que:

$G V_{j}$ é o impacto total, direto e indireto, sobre a variável em questão;

$b_{i j}$ é o ij-ésimo elemento da matriz inversa de Leontief e

$v_{i}$ é o coeficiente direto da variável em questão.

Multiplicadores

A divisão dos geradores pelo coeficiente direto correspondente concebe os multiplicadores, que apontam o quanto é gerado, direta e indiretamente, em termos de emprego, importações, impostos ou qualquer outra variável para cada unidade diretamente gerada desses itens. Neste sentido, pode o multiplicador de emprego indicar a quantidade de empregos criados, direta e indiretamente, para cada emprego direto criado (MILLER; BLAIR, 2009). Portanto, o multiplicador do i-ésimo setor seria dado por:

$$
M V_{i}=\frac{G V_{i}}{v_{i}}
$$

onde $M V_{i}$ representaria o multiplicador da variável em questão e as outras variáveis são definidas conforme feito anteriormente.

Por sua vez, o multiplicador de produção que indica o quanto se produz para cada unidade monetária gasta no consumo final é definido como:

$$
M P_{j}=\sum_{i=1}^{n} b_{i j}
$$

onde $M P_{j}$ é o multiplicador de produção do j-ésimo setor e as outras variáveis são definidas segundo o expresso anteriormente.

Souza, Zapparoli, Sesso Filho et al. (2015), indica que quando o efeito de multiplicação se restringe somente à demanda de insumos intermediários, estes são chamados de multiplicadores do tipo I. Porém, quando a demanda das famílias é endogenizada no sistema, levando-se em consideração o efeito induzido, estes multiplicadores recebem a denominação de multiplicadores do tipo II. Assim, para fins desta pesquisa, os multiplicadores estão restritos ao tipo I.

\section{RESULTADOS E DISCUSSÃO}


As ligações intersetoriais e inter-regionais de determinado sistema econômico são identificadas por meio do estudo das matrizes insumo-produto com o objetivo de analisar a estrutura produtiva dos países membros da Zona do Euro (Alemanha, Áustria, Bélgica, Chipre, Eslováquia, Eslovênia, Estônia, Finlândia, França, Irlanda, Itália, Letônia, Lituânia, Luxemburgo, Malta, Holanda, Portugal, Grécia e Espanha), e seus impactos ambientais com o uso de energia.

\section{Estrutura Produtiva da Zona do Euro}

A criação do euro respondeu ao anseio imediato de alguns países mais fortes de manter sua competitividade, como no caso da Alemanha, mas também de Países Baixos e Áustria, ao mesmo tempo que possibilitava a segmentos econômicos na Grécia e em outros países periféricos uma possibilidade de obter maior acesso a crédito e financiamento a suas respectivas atividades econômicas.

No segundo trimestre de 2008 é registrado a primeira contração do PIB da Zona do Euro desde 1995, sendo que na França o resultado foi decorrente de quedas de 1,5\% dos investimentos e de $2 \%$ das exportações no período; já na Espanha o consumo das famílias recuou em meio ao colapso do setor de construção no país. A queda do consumo privado e dos investimentos em bens de capital e construção caracterizam à contração da economia da Alemanha.

Do ponto de vista econômico, o êxito da União Europeia, apresenta sinais claros de fragilidade no momento em que as dívidas dos governos grego, irlandês e português, bem como seus déficits persistentes, revelaram-se para o mundo, gerando incertezas e apreensões na capacidade de manutenção do euro. Esta foi a primeira crise econômica de maiores proporções da União, provocando desvalorização do Euro, abalo nos mercados mundiais e colocando em xeque a constituição da União Econômica e Monetária baseada nos critérios de convergência econômica entre os países definidos no Tratado de Maastricht (SANDER DINIZ, JAYME JUNIOR, 2013).

Na tabela 2 e na Figura 1 é possível observar o uso de energia em milhões de dólares no ano de 1995 e 2009. Sendo que, os setores de madeira e produto de madeira (6), borracha e plástico (10) e aluguéis (29) destacam-se na utilização de energia renovável, enquanto a representatividade maior com relação ao uso em milhões de dólares de energia não renovável 
FRANÇA, C.I.F.; ZAPPAROLI, I.D.; SESSO FILHO, U.A.

pertence aos setores de refino de petróleo e combustível nuclear (8), transporte aquático (24) e transporte aéreo (25).

Os países da União Europeia destacam-se na aplicação das energias renováveis, deste modo, reduzem as importações energéticas estrangeiras e cumprem as metas fixadas pelo Protocolo de Quioto para redução de emissões de $\mathrm{CO}_{2}$ e combate ao aquecimento global.

Contudo, destaca-se o aumento em 2009 da utilização de energia renovável para os setores de madeira (6), borracha (10) e alugueis (29).

Tabela 2 - Uso de energia dos países da Zona do Euro, 1995 e 2009 (US\$ milhões)

\begin{tabular}{|c|c|c|c|c|c|}
\hline \multirow{3}{*}{$\mathrm{N}$} & \multirow{3}{*}{ Setores } & \multicolumn{4}{|c|}{ Gastos com energias (em US\$) } \\
\hline & & \multicolumn{2}{|c|}{1995} & \multicolumn{2}{|c|}{2009} \\
\hline & & Não Renovável & Renovável & Não Renovável & Renovável \\
\hline 1 & Agropecuária & $1.090 .619,55$ & $129.281,37$ & $823.493,70$ & $188.593,12$ \\
\hline 2 & Extrativismo mineral & $717.425,00$ & $113.912,57$ & $488.781,45$ & $91.874,13$ \\
\hline 3 & Alimentos, bebidas e fumo & $681.026,52$ & $336.616,94$ & $604.725,27$ & $396.077,71$ \\
\hline 4 & Têxteis & $255.320,88$ & $133.345,35$ & $128.854,15$ & $66.522,53$ \\
\hline 5 & Vestuário & $37.207,02$ & $13.616,37$ & $16.558,60$ & $7.854,94$ \\
\hline 6 & Madeira e produtos da madeira & $60.327,16$ & $142.386,05$ & $46.269,89$ & $271.559,75$ \\
\hline 7 & Papel, celulose e gráfica & $479.209,98$ & $506.323,01$ & $397.123,90$ & $752.175,65$ \\
\hline 8 & $\begin{array}{l}\text { Refino de petróleo e } \\
\text { combustível nuclear }\end{array}$ & $23.854 .244,71$ & $130.550,01$ & $22.511 .333,14$ & $183.478,29$ \\
\hline 9 & Indústria química & 4.398.703,97 & $693.706,60$ & $4.285 .093,62$ & $815.001,64$ \\
\hline 10 & Borracha e plástico & $102.712,53$ & $122.176,58$ & $104.796,95$ & $188.127,76$ \\
\hline 11 & Outros minerais não metálicos & $1.120 .016,69$ & $237.882,93$ & $961.974,96$ & $305.350,89$ \\
\hline 12 & Metalurgia & $2.597 .462,29$ & $652.712,12$ & $1.940 .082,59$ & $664.708,42$ \\
\hline 13 & Máquinas e equipamentos & $188.413,21$ & $92.421,12$ & $160.190,03$ & $110.758,15$ \\
\hline 14 & $\begin{array}{l}\text { Eletrônicos e equipamentos } \\
\text { ópticos }\end{array}$ & $144.963,05$ & $102.071,07$ & $115.248,28$ & $106.903,47$ \\
\hline 15 & Equipamentos de transporte & $164.644,11$ & $136.050,05$ & $127.038,90$ & $158.170,78$ \\
\hline 16 & Manufatura e reciclagem & $68.029,70$ & $49.299,81$ & $62.168,38$ & $92.777,23$ \\
\hline 17 & Eletricidade, gás e água & $16.150 .754,85$ & 2.141.389,04 & $17.030 .027,13$ & $3.820 .991,12$ \\
\hline 18 & Construção & $908.231,65$ & $48.344,61$ & $939.022,46$ & $76.441,63$ \\
\hline 19 & $\begin{array}{l}\text { Venda e manutenção de } \\
\text { veículos automotores }\end{array}$ & $148.180,85$ & $54.529,23$ & $127.806,11$ & $78.232,04$ \\
\hline 20 & Atacado & $512.981,23$ & $93.488,28$ & $438.145,38$ & $168.428,88$ \\
\hline 21 & Varejo & $452.868,56$ & $201.158,12$ & $420.755,75$ & $293.702,86$ \\
\hline 22 & Hotéis e restaurantes & $208.494,18$ & $144.963,60$ & $276.911,67$ & $211.273,28$ \\
\hline 23 & Transporte terrestre & $1.549 .940,70$ & $167.462,16$ & $1.783 .872,86$ & $246.067,78$ \\
\hline 24 & Transporte aquático & $691.401,33$ & $4.710,27$ & $932.468,84$ & 593,61 \\
\hline 25 & Transporte aéreo & $1.486 .736,94$ & $1.169,91$ & $1.913 .565,90$ & $2.003,43$ \\
\hline 26 & $\begin{array}{l}\text { Outras atividades de suporte ao } \\
\text { Transporte }\end{array}$ & $357.047,64$ & $39.672,28$ & $328.245,51$ & $100.698,29$ \\
\hline 27 & Comunicações & $230.128,89$ & $46.556,93$ & $193.078,59$ & $96.719,58$ \\
\hline 28 & Intermediação financeira & $109.270,37$ & $59.140,99$ & $123.476,81$ & $79.002,32$ \\
\hline 29 & Aluguéis & $89.713,14$ & $86.317,10$ & $83.817,96$ & $142.979,57$ \\
\hline 30 & Serviços prestados às empresas & $413.385,31$ & $107.179,67$ & $581.298,13$ & $219.620,91$ \\
\hline 31 & Administração pública & $422.603,47$ & $196.901,38$ & $529.113,09$ & $248.488,59$ \\
\hline 32 & Educação & $245.052,94$ & $117.683,24$ & $263.994,76$ & $159.854,77$ \\
\hline 33 & Saúde & $297.350,50$ & $154.008,05$ & $375.183,91$ & $231.891,68$ \\
\hline 34 & Outros serviços & $305.653,49$ & $273.293,38$ & $350.699,61$ & $432.750,55$ \\
\hline
\end{tabular}


Fonte: Elaborado a partir de dados do WIOD (2017).
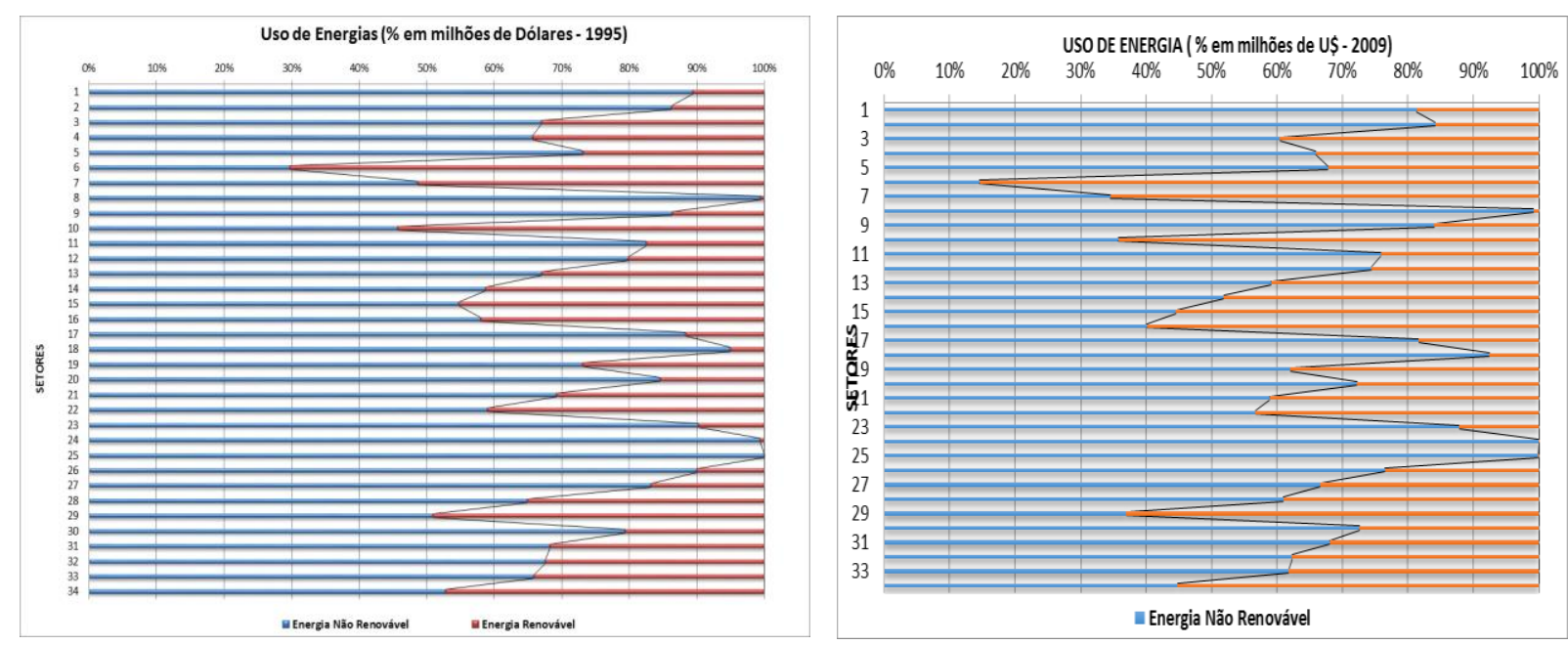

Figura 1 - Uso de energia na Zona do Euro, em 1995 e 2009 (\% em milhões de dólares)

Fonte: Elaborado a partir de dados do WIOD (2017).

Segundo Lourtie (2011), é importante ressaltar a redução da dependência energética para Portugal. Sendo que, a importação de energia contribui para quase metade do déficit da balança comercial. A recente aposta nas energias renováveis é, pois, uma contribuição importante para a correção dos desequilíbrios externos do país. A eletricidade gerada a partir de fontes renováveis constituiu em 2010 50,2\% do total de produção elétrica acrescido de importações líquidas, um crescimento em relação aos 33,9\% de 2003.

\section{Multiplicador de Energia dos países da Zona do Euro}

A fim de avaliar a relação da estrutura produtiva dos países membros da Zona do Euro com à utilização de energia, foram calculados os multiplicadores de energia para cada setor de produção dos países deste grupo. Dessa forma, este multiplicador busca mensurar à utilização de energia em milhões de dólares de cada um dos 34 setores, seja de forma direta ou indireta. Portanto, quando houver um aumento na demanda final, por exemplo, há, consequentemente, mais utilização de energia renovável ou não renovável, tanto sobre o próprio setor que a atende (efeito direto), como também sobre todo o restante da economia, devido à necessidade de aquisição de insumos e transporte dos produtos (efeito indireto).

Sesso Filho, Rodrigues e Moretto (2017) indicam que as diferenças dos sistemas econômicos determinam os fluxos de bens e serviços inter-regionais e intra-regionais, fazendo 
com que variações da produção de determinado setor em dada região tenham impacto em todo o sistema indiretamente (efeito multiplicador de produção).

Os resultados importantes para o multiplicador de energia de cada setor dos países que compõem a Zona do Euro, no que tange ao uso da energia para os anos de 1995 e 2009 estão dispostos na tabela 3 e na figura 2 .

Tabela 3 - Multiplicador de energia dos países da Zona do Euro, 1995 e 2009

\begin{tabular}{|c|c|c|c|c|c|}
\hline \multirow{2}{*}{$\mathbf{N}$} & \multirow{2}{*}{ Setores } & \multicolumn{2}{|c|}{ Energia não renovável } & \multicolumn{2}{|c|}{ Energia renovável } \\
\hline & & 1995 & 2009 & 1995 & 2009 \\
\hline 1 & Agropecuária & 3,29 & 2,56 & 1,38 & 1,41 \\
\hline 2 & Extrativismo mineral & 1,63 & 1,10 & 1,23 & 1,19 \\
\hline 3 & Alimentos, bebidas e fumo & 5,94 & 3,99 & 1,09 & 1,95 \\
\hline 4 & Têxteis & 5,25 & 3,48 & 1,10 & 1,80 \\
\hline 5 & Vestuário & 8,74 & 5,28 & 1,57 & 1,15 \\
\hline 6 & Madeira e produtos da madeira & 3,72 & 2,87 & 1,40 & 1,82 \\
\hline 7 & Papel, celulose e gráfica & 2,80 & 1,91 & 1,00 & 1,03 \\
\hline 8 & Refino de petróleo e combustível nuclear & 1,14 & 0,41 & 1,02 & 1,01 \\
\hline 9 & Indústria química & 1,98 & 1,35 & 1,28 & 1,22 \\
\hline 10 & Borracha e plástico & 8,61 & 6,24 & 1,85 & 1,72 \\
\hline 11 & Outros minerais não metálicos & 2,12 & 1,49 & 1,35 & 1,34 \\
\hline 12 & Metalurgia & 2,64 & 1,52 & 1,50 & 1,36 \\
\hline 13 & Máquinas e equipamentos & 11,39 & 7,44 & 2,16 & 1,73 \\
\hline 14 & Eletrônicos e equipamentos ópticos & 12,70 & 9,22 & 2,48 & 2,13 \\
\hline 15 & Equipamentos de transporte & 13,76 & 9,23 & 2,77 & 2,24 \\
\hline 16 & Manufatura e reciclagem & 10,32 & 7,05 & 2,28 & 2,13 \\
\hline 17 & Eletricidade, gás e água & 1,22 & 0,76 & 1,15 & 1,16 \\
\hline 18 & Construção & 8,19 & 5,09 & 2,15 & 1,91 \\
\hline 19 & Venda e manutenção de veículos automotores & 5,66 & 3,71 & 1,93 & 1,80 \\
\hline 20 & Atacado & 6,68 & 4,53 & 1,80 & 1,73 \\
\hline 21 & Varejo & 4,10 & 2,67 & 1,72 & 1,67 \\
\hline 22 & Hotéis e restaurantes & 6,39 & 3,80 & 1,26 & 1,97 \\
\hline 23 & Transporte terrestre & 2,97 & 2,04 & 1,22 & 1,19 \\
\hline 24 & Transporte aquático & 1,64 & 0,87 & 1,05 & 1,03 \\
\hline 25 & Transporte aéreo & 1,58 & 1,29 & 1,04 & 1,04 \\
\hline 26 & Outras atividades de suporte ao Transporte & 5,32 & 3,44 & 1,51 & 1,48 \\
\hline 27 & Comunicações & 3,44 & 2,47 & 1,48 & 1,56 \\
\hline 28 & Intermediação financeira & 8,37 & 5,45 & 1,50 & 1,25 \\
\hline 29 & Aluguéis & 8,76 & 4,70 & 1,70 & 1,30 \\
\hline 30 & Serviços prestados às empresas & 7,17 & 4,75 & 1,10 & 1,97 \\
\hline 31 & Administração pública & 4,28 & 2,97 & 1,80 & 1,66 \\
\hline 32 & Educação & 3,02 & 1,95 & 1,63 & 1,51 \\
\hline 33 & Saúde & 5,79 & 3,61 & 1,09 & 1,84 \\
\hline 34 & Outros serviços & 3,80 & 2,45 & 1,94 & 1,81 \\
\hline
\end{tabular}

Fonte: Elaborado a partir de dados do WIOD (2017).

Silva (2016) indica que o grau de interdependência entre os setores produtivos de uma dada região, ou cadeia de produção, pode ser dada por meio do multiplicador de produção. Sendo que, os multiplicadores e geradores de produção incorporam os efeitos diretos e indiretos do impacto de um choque na demanda final setorial na produção total. 
No entanto, Brene (2013) assinala que, o impacto direto ocorre dentro do próprio setor que atende ao aumento da demanda final, e o impacto indireto influencia os setores ofertantes de insumos da região local e dos setores de outras regiões.

Em 1995 e 2009, os setores que se destacam são: máquinas e equipamentos (13), eletrônicos e equipamentos ópticos (14) e equipamentos de transporte (15), uma vez que apresentam os maiores multiplicadores de energia no período analisado. Assim, por exemplo, em 1995 no setor de equipamentos e transportes, um aumento de 1 TJ no setor gera a necessidade de 13,76 TJ na economia como um todo. Já em 2009, no setor de equipamentos e transportes, o aumento de $1 \mathrm{TJ}$ no setor gera a necessidade de 9,23 TJ na economia como um todo.

Energia não renovável

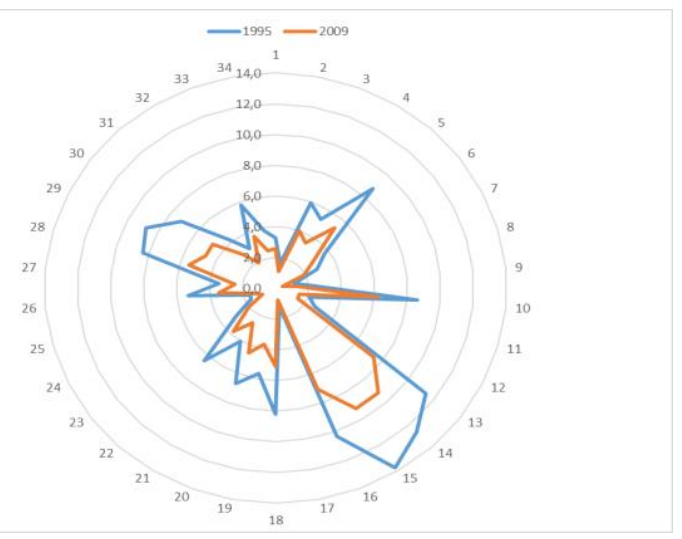

Energia renovável

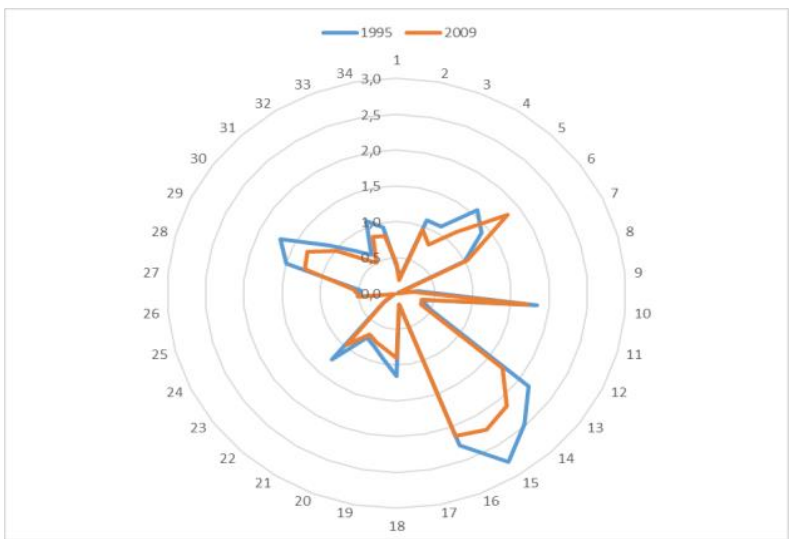

Figura 2 - Multiplicador de energia não renovável e renovável dos países da Zona do Euro, 1995 e 2009

Fonte: Elaborado a partir de dados do WIOD (2017).

É evidenciado na tabela 4 e na figura 2 os resultados para o multiplicador de energia para cada setor dos países da Zona do Euro no que diz respeito ao uso da energia renovável para os anos de 1995 e 2009. Portanto, os setores que se destacam devido à apresentarem os maiores multiplicadores de energia no período analisado são: eletrônicos e equipamentos ópticos (14), equipamentos de transporte (15) e manufatura e reciclagem (16). Assim, em 1995 no setor de equipamentos e transportes, um aumento de 1 TJ no setor gera a necessidade de 2,77 TJ na economia como um todo. Já em 2009, o aumento de 1 TJ no setor de equipamentos e transportes gera a necessidade de 2,24 TJ na economia como um todo.

Em síntese, os setores que apresentaram os maiores multiplicadores de energia dos países da Zona do Euro em relação ao uso de energia não renovável, cuja mensuração foi efetuada em terajoule (TJ) para os anos de 1995 e 2009, foram: máquinas e equipamentos 
(13), eletrônicos e equipamentos ópticos (14) e equipamentos de transporte (15). Portanto o destaque para os setores no uso de energia renovável para os anos de 1995 e 2009 foram: eletrônicos e equipamentos ópticos (14), equipamentos de transporte (15) e manufatura e reciclagem (16). Sendo esses, portanto, os setores-chave na produção dos países do bloco analisado, bem como, os setores da economia que mais contribuíram para o aumento do uso de energia durante o período analisado.

De modo geral, tais resultados possibilitam identificar os setores mais intensivos em utilização de energia renovável e não renovável, uma vez que, quando há um aumento na produção de um deles, isso faz com que essa atividade demande uma produção adicional dos demais setores, sendo justamente esse aumento no produto dos demais setores e consequentemente sua utilização de energia, que exerce impacto relativamente forte na economia.

\section{Gerador de Energia dos países da Zona do Euro}

O gerador de produção de energia indica a quantidade gerada direta e indiretamente de energia que corresponde a uma unidade monetária de demanda final. Dessa forma, o cálculo da geração de energia renovável e não renovável para a Zona do Euro, foi realizado a fim de identificar os efeitos sobre o uso da energia correspondente a cada setor. Provocados por uma variação na demanda final em US\$ 1 milhão, cujos resultados estão em terajoule (TJ) de energia por milhão de dólares em 1995 e 2009. A tabela 4 e a figura 3 apresentam alguns resultados importantes quanto aos geradores de energia não renovável de cada um dos setores que compõem a Zona do Euro para os anos de 1995 e 2009.

Tabela 4 - Gerador de Energia dos países da Zona do Euro, 1995 e 2009 (US\$ 1 milhão)

\begin{tabular}{c|l|cccc}
\hline \multirow{2}{*}{$\boldsymbol{N}^{\boldsymbol{*}}$} & \multirow{2}{*}{ Setores } & \multicolumn{2}{c}{ Energia Não Renovável } & \multicolumn{2}{c}{ Energia Renovável } \\
\cline { 3 - 6 } & & $\mathbf{1 9 9 5}$ & $\mathbf{2 0 0 9}$ & $\mathbf{1 9 9 5}$ & $\mathbf{2 0 0 9}$ \\
\hline 1 & Agropecuária & 11,17 & 8,68 & 1,30 & 1,41 \\
2 & Extrativismo mineral & 17,48 & 11,85 & 2,49 & 2,05 \\
3 & Alimentos, bebidas e fumo & 9,78 & 6,58 & 1,80 & 1,57 \\
4 & Têxteis & 9,90 & 6,56 & 2,07 & 1,50 \\
5 & Vestuário & 8,40 & 5,08 & 1,51 & 1,11 \\
6 & Madeira e produtos da madeira & 8,52 & 6,59 & 3,20 & 4,17 \\
7 & Papel, celulose e gráfica & 9,20 & 6,28 & 3,28 & 3,38 \\
8 & Refino de petróleo e combustível & 208,84 & 75,31 & 3,63 & 2,14 \\
& nuclear & & & & \\
9 & Indústria química & 24,72 & 16,87 & 3,56 & 2,76 \\
10 & Borracha e plástico & 11,98 & 8,69 & 2,57 & 2,40 \\
11 & Outros minerais não metálicos & 17,55 & 12,33 & 2,88 & 2,81
\end{tabular}




\begin{tabular}{|c|c|c|c|c|c|}
\hline 12 & Metalurgia & 16,69 & 9,63 & 3,13 & 2,26 \\
\hline 13 & Máquinas e equipamentos & 8,21 & 5,36 & 1,56 & 1,25 \\
\hline 14 & $\begin{array}{l}\text { Eletrônicos e equipamentos } \\
\text { ópticos }\end{array}$ & 7,57 & 5,50 & 1,48 & 1,27 \\
\hline 15 & Equipamentos de transporte & 8,67 & 5,82 & 1,75 & 1,41 \\
\hline 16 & Manufatura e reciclagem & 8,52 & 5,82 & 1,88 & 1,76 \\
\hline 17 & Eletricidade, gás e água & 58,64 & 36,90 & 7,39 & 7,71 \\
\hline 18 & Construção & 8,03 & 4,99 & 1,13 & 0,89 \\
\hline 19 & $\begin{array}{l}\text { Venda e manutenção de veículos } \\
\text { automotores }\end{array}$ & 5,62 & 3,69 & 0,93 & 0,79 \\
\hline 20 & Atacado & 6,15 & 4,18 & 0,74 & 0,67 \\
\hline 21 & Varejo & 5,35 & 3,49 & 0,94 & 0,88 \\
\hline 22 & Hotéis e restaurantes & 6,32 & 3,76 & 1,24 & 0,96 \\
\hline 23 & Transporte terrestre & 16,96 & 11,64 & 1,25 & 1,08 \\
\hline 24 & Transporte aquático & 32,25 & 17,06 & 0,97 & 0,67 \\
\hline 25 & Transporte aéreo & 34,54 & 28,18 & 0,77 & 0,81 \\
\hline 26 & $\begin{array}{l}\text { Outras atividades de suporte ao } \\
\text { Transporte }\end{array}$ & 9,46 & 6,10 & 0,90 & 0,86 \\
\hline 27 & Comunicações & 4,48 & 3,22 & 0,62 & 0,73 \\
\hline 28 & Intermediação financeira & 2,46 & 1,60 & 0,44 & 0,37 \\
\hline 29 & Aluguéis & 1,72 & 0,92 & 0,33 & 0,26 \\
\hline 30 & Serviços prestados às empresas & 3,60 & 2,38 & 0,55 & 0,49 \\
\hline 31 & Administração pública & 4,12 & 2,85 & 0,77 & 0,63 \\
\hline 32 & Educação & 2,83 & 1,83 & 0,59 & 0,48 \\
\hline 33 & Saúde & 4,47 & 2,79 & 0,84 & 0,65 \\
\hline 34 & Outros serviços & 5,18 & 3,34 & 1,28 & 1,11 \\
\hline
\end{tabular}

Fonte: Elaborado a partir de dados do WIOD (2017).

Miller e Blair (2009), identificam que, cada setor da economia pode estimar o quanto é gerado direta e indiretamente de emprego, importações, impostos, salários, valor adicionado ou outra variável de interesse para cada unidade monetária produzida para a demanda final.

Em 1995 e 2009, observa-se que o setor de Refino de Petróleo e Combustível Nuclear (8) se destaca como o setor que mais utiliza energia não renovável, por aumento da demanda final deste bloco. Assim, por exemplo, em 1995 uma variação da demanda final deste setor em US\$ 1 milhão, provoca um aumento de 208,84 TJ na utilização de energia não renovável em toda a economia, e em 2009 uma variação da demanda final deste setor em US\$ 1 milhão, provoca um aumento de 75,31 TJ, uma vez que, no intuito de atender este aumento da demanda final, o setor de Refino de Petróleo e Combustível Nuclear irá aumentar sua produção, assim como os demais setores que fornecem os insumos, causando, portanto, um efeito adicional na utilização de energia não renovável.

Seguidamente, tem-se que os setores de Eletricidade, Gás e Água (17) e Transporte Aéreo (25) que mais contribuíram para o aumento total da utilização de energia não renovável no período analisado. 
Energia não renovável

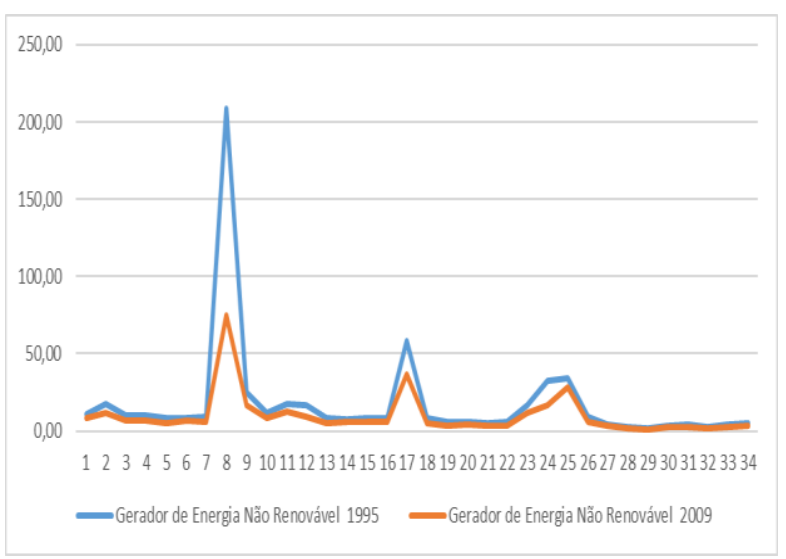

Energia renovável

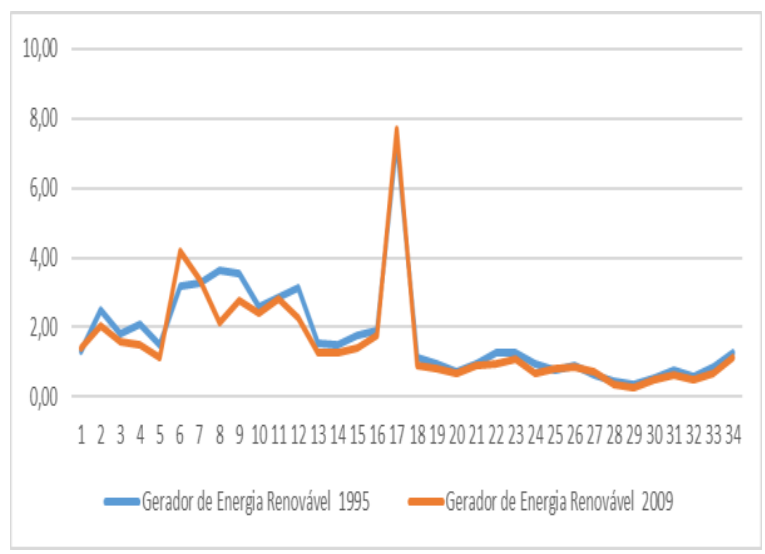

Figura 3 - Gerador de energia não renovável e renovável dos países da Zona do Euro, 1995 e 2009

Fonte: Elaborado a partir de dados do WIOD (2017).

É possível observar na tabela 5 e na figura 4 os geradores de produção de energia renovável para os anos de 1995 e 2009, com destaque para o setor de Eletricidade, Gás e Água (17) que mais utiliza energia renovável, por aumento da demanda final deste bloco.

Portanto, em 1995, uma variação da demanda final deste setor em US\$ 1 milhão, provoca um aumento de 7,39 TJ na utilização de energia renovável em toda a economia, e em 2009 uma variação da demanda final deste setor em US\$ 1 milhão, provoca um aumento de 7,71 TJ, uma vez que, no intuito de atender este aumento da demanda final, o setor de Eletricidade, gás e água irá aumentar sua produção, assim como os demais setores que fornecem os insumos, causando, portanto, um efeito adicional na utilização de energia renovável. Seguidamente, em 1995 temos que os setores de Refino de Petróleo (8) e Indústria Química (9) e em 2009 Madeira e Produtos de Madeira (6) e Papel, Celulose e Gráfica (7) são os setores localizados na Zona do Euro que mais contribuíram para o aumento total da utilização de energia renovável no período analisado.

Em síntese, os setores que apresentaram os maiores geradores de energia renovável e energia não renovável dos países da Zona do Euro em 1995 e 2009 foram: Refino de Petróleo e Combustível Nuclear (8) e Eletricidade, Gás e Água (17), sendo que, contribuíram para a utilização de energia no período analisado.

\section{Transbordamento da utilização de energia dos países da Zona do Euro}

Um estudo complementar ao gerador de energia é o efeito transbordamento, o qual mensura o aumento da utilização de energia renovável e não renovável do setor sobre as 
atividades econômicas que estão fora de sua região de origem. Nesse sentido, este indicador evidencia o quanto o uso de energia fica dentro do bloco e o quanto é transbordado para fora dele.

No entanto, a tabela 5 e a figura 4 apresentam os resultados do transbordamento da utilização da energia não renovável para cada setor da Zona do Euro, para os anos de 1995 e 2009 em valores percentuais

Em 1995 e 2009, os setores que se destacam são: Eletrônicos e equipamentos ópticos (14) e Equipamentos de transporte (15) indicando que grande parte da utilização da energia não renovável proveniente do aumento da produção desses setores, é transbordado para fora do bloco, impactando, portanto, a economia do restante dos países do mundo.

A figura 4 e a tabela 5 evidenciam os resultados importantes do transbordamento da utilização da energia renovável para cada setor da Zona do Euro, para os anos de 1995 e 2009 em valores percentuais.

Tabela 2 - Transbordamento da utilização de energia dos países da Zona do Euro, 1995 e 2009 (\%)

\begin{tabular}{|c|c|c|c|c|c|}
\hline \multirow[t]{2}{*}{$\mathbf{N}^{\mathbf{o}}$} & \multirow[t]{2}{*}{ SETORES } & \multicolumn{2}{|c|}{$\begin{array}{c}\text { Transbordamento de Energia Não } \\
\text { Renovável }\end{array}$} & \multicolumn{2}{|c|}{$\begin{array}{c}\text { Transbordamento de Energia } \\
\text { Renovável }\end{array}$} \\
\hline & & 1995 & 2009 & 1995 & 2009 \\
\hline 1 & Agropecuária & 19,59 & 30,86 & 28,05 & 24,89 \\
\hline 2 & Extrativismo mineral & 11,73 & 18,30 & 13,26 & 13,93 \\
\hline 3 & Alimentos, bebidas e fumo & 24,84 & 33,82 & 25,45 & 23,17 \\
\hline 4 & Têxteis & 29,03 & 39,71 & 28,70 & 32,36 \\
\hline 5 & Vestuário & 31,30 & 40,94 & 36,09 & 34,52 \\
\hline 6 & Madeira e produtos da madeira & 29,14 & 38,06 & 18,47 & 10,99 \\
\hline 7 & Papel, celulose e gráfica & 25,82 & 32,51 & 17,15 & 12,94 \\
\hline 8 & $\begin{array}{l}\text { Refino de petróleo e } \\
\text { combustível nuclear }\end{array}$ & 6,09 & 13,36 & 52,86 & 56,39 \\
\hline 9 & Indústria química & 19,43 & 30,58 & 25,64 & 29,24 \\
\hline 10 & Borracha e plástico & 34,07 & 45,22 & 33,85 & 31,72 \\
\hline 11 & Outros minerais não metálicos & 15,09 & 21,31 & 15,45 & 13,43 \\
\hline 12 & Metalurgia & 25,65 & 35,03 & 26,79 & 27,01 \\
\hline 13 & Máquinas e equipamentos & 34,50 & 45,59 & 36,14 & 36,58 \\
\hline 14 & $\begin{array}{l}\text { Eletrônicos e equipamentos } \\
\text { ópticos }\end{array}$ & 40,52 & 53,31 & 41,36 & 44,11 \\
\hline 15 & Equipamentos de transporte & 36,03 & 49,17 & 36,10 & 39,14 \\
\hline 16 & Manufatura e reciclagem & 34,70 & 43,06 & 34,86 & 26,83 \\
\hline 17 & Eletricidade, gás e água & 6,20 & 10,01 & 6,99 & 6,72 \\
\hline 18 & Construção & 26,08 & 36,39 & 33,99 & 32,16 \\
\hline 19 & $\begin{array}{l}\text { Venda e manutenção de } \\
\text { veículos automotores }\end{array}$ & 25,22 & 37,02 & 25,72 & 25,36 \\
\hline 20 & Atacado & 23,69 & 36,71 & 29,26 & 26,51 \\
\hline 21 & Varejo & 21,13 & 29,06 & 18,56 & 15,86 \\
\hline 22 & Hotéis e restaurantes & 22,05 & 31,04 & 20,46 & 18,71 \\
\hline 23 & Transporte terrestre & 16,70 & 29,92 & 20,54 & 21,88 \\
\hline 24 & Transporte aquático & 12,24 & 22,84 & 39,51 & 44,04 \\
\hline 25 & Transporte aéreo & 10,13 & 19,93 & 44,54 & 51,07 \\
\hline 26 & Outras atividades de suporte & 21,67 & 35,28 & 29,10 & 25,55 \\
\hline
\end{tabular}


FRANÇA, C.I.F.; ZAPPAROLI, I.D.; SESSO FILHO, U.A.

\begin{tabular}{l|lrrrr} 
& ao Transporte & & & & \\
27 & Comunicações & 21,19 & 35,24 & 23,13 & 23,89 \\
28 & Intermediação financeira & 27,79 & 38,71 & 25,71 & 27,39 \\
29 & Aluguéis & 24,61 & 33,72 & 22,01 & 18,96 \\
30 & Serviços prestados às & 26,83 & 36,68 & 28,61 & 26,16 \\
& empresas & & & \\
31 & Administração pública & 22,31 & 31,19 & 19,64 & 20,25 \\
32 & Educação & 17,32 & 25,34 & 13,53 & 13,02 \\
33 & Saúde & 27,12 & 38,85 & 27,87 & 29,53 \\
34 & Outros serviços & 22,15 & 31,67 & 15,07 & 14,26 \\
\hline
\end{tabular}

Fonte: Elaborado a partir de dados do WIOD (2017).

Assim, por exemplo, em 1995 no setor de Eletrônicos e Equipamentos Ópticos observa-se que aproximadamente $41 \%$ da utilização de energia não renovável foram geradas fora da Zona do Euro, enquanto em 2009 o percentual foi de aproximadamente 54\%, o que significa que quando a produção deste setor aumenta, cerca da metade da utilização de energia não renovável gerada são de setores instalados fora desse bloco.

Em 1995 e 2009, os setores que se destacam são: Refino de Petróleo e Combustível Nuclear (8) e Transporte Aéreo (25), os quais indicam que grande parte da utilização da energia não renovável proveniente do aumento da produção desses setores, é transbordado para fora do bloco, impactando, portanto, a economia do restante dos países do mundo. Portanto, em 1995 no setor de Refino de Petróleo e Combustível Nuclear verifica-se que aproximadamente $53 \%$ da utilização de energia não renovável foram geradas fora da Zona do Euro, sendo que, em 2009 este percentual é aproximadamente 57\%, o que significa que quando a produção deste setor aumenta, mais da metade da utilização de energia não renovável gerada são de setores instalados fora desse bloco.

\section{Energia não renovável}

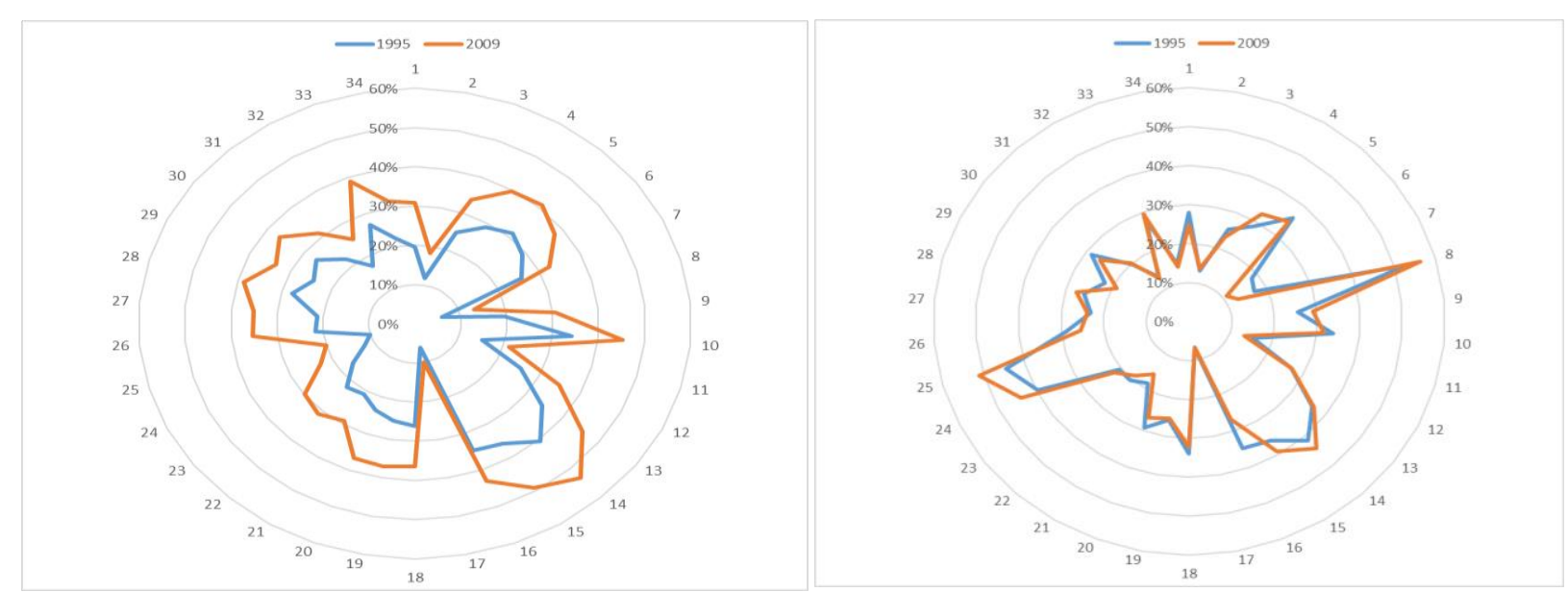

Figura 4 - Transbordamento da utilização de energia não renovável e renovável dos países da Zona do Euro, 1995 e 2009, (\%)

Fonte: Elaborado a partir de dados do WIOD (2017). 
Assim, é possível observar que a Zona do Euro possui grande transbordamento em relação à utilização de energia renovável e não renovável, confirmando assim que as cadeias produtivas da Zona do Euro são limpas, em comparação aos demais países de fora do bloco. Ou seja, importam insumos para a produção, aplicando assim, uma estratégia ambiental preventiva e integrada aos processos e produtos, no sentido de aumentar a eficiência e reduzir os riscos a sociedade e ao meio ambiente.

\section{CONSIDERAÇÕES FINAIS}

A pesquisa permite concluir que o setor de refino de petróleo e combustível nuclear se destaca na utilização de energia renovável e não renovável no período analisado. No que diz respeito ao cálculo dos multiplicadores de produção o setor de Equipamentos de Transporte apresentou os dados mais significativos dos países da Zona do Euro em relação ao uso de energia renovável e energia não renovável, cuja mensuração foi efetuada em terajoule para os anos de 1995 e 2009. Sendo este, o setor-chave na produção dos países do bloco analisado, bem como, o setor da economia que mais contribuiu para o aumento do uso de energia durante o período analisado.

Quanto à identificação do gerador de energia, observa-se com relação a energia não renovável que, em 1995 e 2009, o setor de Refino de Petróleo e Combustível Nuclear se destaca como o setor que mais utiliza energia por aumento da demanda final deste bloco. No entanto, no que se refere à relação do gerador de energia renovável, o setor de destaque é Eletricidade, Gás e Água. Neste sentido os setores irão aumentar sua produção, assim como os demais setores que fornecem os insumos, causando, portanto, um efeito adicional na utilização de energia.

No que que se refere a estimativa do efeito transbordamento da utilização de energia não renovável, em 1995 e 2009, o setor que se destaca é Eletrônicos e Equipamentos Ópticos. Porém, no que é pertinente ao transbordamento de energia renovável, o setor que se destaca é Refino de Petróleo e Combustível Nuclear indicando que grande parte da utilização de energia proveniente do aumento da produção desses setores, é transbordado para fora do bloco, impactando, assim, a economia do restante dos países do mundo.

Portanto, o estudo verificou que na Zona do Euro os resultados observados mostram que grande parte da utilização de energia, provenientes do aumento da produção, é transbordada para fora desse bloco. Porém, cabe destacar que este é um importante indicativo da dependência da Zona do Euro de insumos importados, devido, sobretudo, à sua insuficiente infraestrutura interna. Desse modo, em razão de tal dependência, utiliza menos energia em 
relação aos demais países, pois a medida que importa tais insumos, consequentemente, utiliza energia em outros países.

Cabe, ainda, destacar que a partir da análise dos resultados, pôde identificar a presença de um trade-off que os países membros da Zona do Euro enfrentam, entre o aumento da produção e a utilização de energia. Resta, portanto, descobrir quais são as vantagens e desvantagens de cada país quanto a estas escolhas, ficando essa discussão como sugestão para trabalhos futuros. Outra análise interessante seria analisar a variação da utilização de energia na matriz mundial do WIOD, por meio da decomposição estrutural da variação de energia em efeito intensidade.

\section{REFERÊNCIAS BIBLIOGRÁFICAS}

BRENE, P. R. A. Ensaios sobre o uso da matriz insumo-produto como ferramenta de políticas públicas municipais. Tese (Doutorado) - Universidade Federal do Paraná, Setor de Ciências Sociais Aplicadas, Programa de Pós-Graduação em Desenvolvimento Econômico, Curitiba, 2013.

CASLER, S. D.; BLAIR, P. D. Economic structure, fuel combustion, and pollution emissions. Ecological Economics, Amsterdam, v. 22, p. 19-27, 1997.

CUMBERLAND, J. H. A regional interindustry model for analysis of development objectives. Papers in Regional Science, Rotterdam, v. 17, p. 65-94, 1966.

DALY, H. E. On economics as a life science. Journal of Political Economy, Chicago, v. 76, n. 1, p. 392-406, 1969.

ECOD. Ecodesenvolvimento. Energia, 2010. Disponível em

$<$ http://www.ecodesenvolvimento.org /noticias /energia-renovavel-responde-por-20-doconsumo-na/\#>>. Acesso em: 03 ago. 2017.

ESTEVES, E. G. Z. Dinâmica mundial do uso da energia renovável, energia não renovável e da emissão de CO2 por níveis de IDH: 1995 a 2009. Tese (doutorado) Universidade Estadual de Maringá, Departamento de Economia, Programa de Pós-Graduação em Economia, 2017.

FERREIRA NETO, A. B.; PEROBELLI, F. S.; BASTOS, S. Q. A. Estrutura de demanda e uso de energia: uma análise de insumo-produto para países selecionados (1995 e 2005). In: Encontro Nacional de Economia da ANPEC, 40., Porto de Galinhas, 2012. Anais... Porto de Galinhas: ANPEC, 2012.

FIRME, V. A. C.; Perobelli, F. S. O setor energético brasileiro: uma análise via indicadores de insumo-produto e o modelo híbrido para os anos de 1997 e 2002. Planejamento e Políticas Públicas, Brasília, v. 39, p. 123-153, jul./dez. 2012.

GOLDEMBERG, J.; LUCON, O. Energia, meio ambiente e desenvolvimento. 3. ed. São Paulo: EDUSP, 2008.

GUILHOTO, J. et al. Estimação da Matriz Insumo-Produto Utilizando Dados

Preliminares das Contas Nacionais: Aplicação e Análise de Indicadores Econômicos para o Brasil em 2005 (Using Data from the System of National Accounts to Estimate Input-Output Matrices: An Application Using Brazilian Data for 2005). 2010. 
GUILHOTO, J. J. M. Leontief e insumo-produto: antecedentes, princípios e evolução. Piracicaba: ESALQ, 2001.

HINRICHS, R. A.; KLEINBACH, M.; REIS, L. B. Energia e meio ambiente. 5. ed. São Paulo: Cengage Learning, 2014.

LEONTIEF, W. A economia do insumo-produto. 3. ed. São Paulo: Nova cultural, 1988. 1951.

The structure of the American economy. 2. ed. New York: Oxford University Press,

LEONTIEF, W.; FORD, D. Air pollution and economic structure: empirical results of inputoutput computations. In: Brody, A.; Carter, A. P. (Ed.). Input-output techniques.

Amsterdam: North-Holland Publishing, 1972. p. 9-30.

Liu, H. et al. Energy embodied in the international trade of China: an energy input-output analysis. Energy Policy, Surrey, v. 38, n. 8, p. 3957-3964, 2010.

LOURTIE, P. Portugal no contexto da crise do euro. Relações Internacionais R: I, Lisboa, n. 32, p. 61-105, 2011.

MACHADO, G.; SCHAEFFER, R.; WORRELL, E. Energy and carbon embodied in the international trade of Brazil: an input-output approach. Ecological Economics, Amsterdam, v. 39, n. 3, p. 409-424, 2001.

MATTOS, R. S. et al. Integração de modelos econométrico e de insumo-produto para previsões de longo prazo da demanda de energia no Brasil. Estudos Econômicos, São Paulo, v. 38, n. 4, p. 675-699, out./dez. 2008.

Mentone, F. A. Energia renovável e desenvolvimento. São Paulo: PUC, 2015.

MILLER, R.; BLAIR, P. D. Input-output analysis: foundations and extensions. Cambridge: Cambridge University Press, 2009.

MONTOYA, M. A.; PASQUAL, C. A. O uso setorial de energia renovável versus não renovável e as emissões de $\mathrm{CO} 2$ na economia brasileira: um modelo insumo-produto híbrido para 53 setores. Pesquisa e Planejamento Econômico, Rio de Janeiro, v. 45, n. 2, p. 289334, ago. 2015.

PARLAMENTO EUROPEU. Energias Renováveis. Disponível em: <http://www.europarl.europa.eu /atyourservice/pt/displayFtu.html?ftuId=FTU_5.7.4.html> Acesso em: 1 ago. 2017.

PORTAL ENERGIA. União Europeia comprometida com metas de energias renováveis. 2011. Disponível em < https://www.portal-energia.com/uniao-europeia-comprometida-commetas-nas-energias-renovaveis/>. Acesso em: 04 ago. 2017.

REN21. Renewable Energy Policy Network for the 21st Century. Renewables: Global Status Report, Paris, 2010. Disponível em: Disponível em: <http://www.ren21.net/status-ofrenewables/global-status-report/>. Acesso em: 18 abr. 2017.

SANDER DINIZ, A.; JAYME JUNIOR, F. G. Competitividade e restrição externa na Zona do Euro. Revista de Economia Política, São Paulo, v. 33, n. 1, p. 17, 2013. Disponível em: <http://www.rep.org.br/PDF /130-2.PDF>. Acesso em: 18 abr. 2017.

SANTIN, M. F. C L.; ALVIM, A. M. Os impactos da demanda por crédito de carbono sobre o mercado de certificações de reduções de emissões no Brasil. Ensaios FEE, Porto Alegre, v. 29, n. 2, p. 531-564, 2008.

SESSO FILHO, U. A.; RODRIGUES, R. L.; MORETTO, A. C. Decomposição do efeito multiplicador de produção e emprego no sistema inter-regional sul-restante do Brasil. Disponível em > <http://www.ecopar.ufpr.br/artigos/a7_032.pdf>. Acesso em: 13 jul. 2017. 
SILVA, R. J. Evolução das interligações produtivas do Brasil nas cadeias globais de valor de 1995 a 2009. 2016. 111f. Dissertação (Mestrado em Economia Regional) - Universidade Estadual de Londrina, Londrina, 2016.

SIMAS, M. S. Energia eólica e desenvolvimento sustentável no Brasil: estimativa da geração de empregos por meio de uma matriz insumo-produto ampliada. 2012. Dissertação (Mestrado em Ciências) - Universidade de São Paulo, São Paulo, 2012.

SOUZA, A. M.; ZAPPAROLI, I. D.; SESSO FILHO, U. A.; BRENE, P. R. A. Estrutura produtiva do Brasil, Rússia, Índia e China (BRIC) e seus impactos nas emissões de dióxido de carbono $\left(\mathrm{CO}_{2}\right)$. Revista Desenvolvimento e Meio Ambiente, Vol. 34, p.27-50, ago. 2015. TANG, XU; SNOWDEN, S.; HÖÖK, M. Analysis of energy embodied in the international trade of UK. Energy Policy, Surrey, v. 57, p. 418-428, 2013.

TIMMER, M. P. (Ed.). The world input-output database (WIOD): contents, sources and methods. 2012. (WIOD Working Paper N. 10). Disponível em:

<http://www.wiod.org/database/index.htm>. Acesso em: 18 abr. 2017.

VICHI, F. M.; MANSOR, M. T. C. Energia, meio ambiente e economia: o Brasil no contexto mundial. Química Nova, São Paulo, v. 32, n. 3, p. 757-767, 2009.

WIOD. World Input-Output Database. Disponível em: <http://www.wiod.org>. Acesso em: 13 jan. 2017.

Recebido em 04 de dezembro de 2017.

Aceito em 02 de fevereiro de 2018. 